\title{
Overall growth of the lamb: its characteristics and rules
}

\author{
M. PRUD'HON
}

Station de Physiologie aninale, I.N.R.A., E.N.S.A. place Viala, 34060 Montpellier Cedex

A descriptive study of the prenatal and post-natal growth of the lamb and the methods used to determine its characteristics was made.

Unpublished data on the dissection of 80 lambs belonging to 5 different genotypes (Romanov, Merino, Romanov $\times$ Merino, Berrichon, Berrichon $\times$ Merino) slaughtered at 25,50 , Ioo and I5o days of age were used.

Breed comparisons were done at similar degrees of maturity (slaughter weight/adult weight) The results show large breed differences in the growth of various organs and fat deposits but not in the proportions of muscles and bones. These differences decreased when degree of maturity reached 0.25 to 0.60 .

The allometric coefficient of empty liveweight or total mass of similar tissue was also used to characterize the grow th of different organs and tissues. The usual rules for differential growth were verified for each genotype studied; however, there are some differences in the magnitude of the allometric coefficient in these 5 genotypes. Roughly, this magnitude varied less in the muscle tissue from one genotype to another. However, there are differences in muscle mass distribution, i.e. at the same degree of maturity, the Romanov and the Merino had more shoulder muscle and less leg muscle than the Berrichon.

The prerequisites for an inventory of growth characteristics and anatomical composition of the main French sheep breeds are outlined. The utilisation of simple estimators for predicting growth is suggested.

\section{General aspects of the development and growth of muscle and adipose tissues : characteristics in sheep}

\author{
A. VEZINHET, J. NOUGUES and P. VIGNERON \\ Station de Physiologie animale, I.N.R.A., E.N.S.A., place Viala, 3 fo60 Montpellier Cedex
}

The aim in meat production is to increase the muscle mass (which is the protein fraction) in the carcass and obtain an optimal amount of fatty tissue. To satisfy these objectives, it is necessary to have a better knowledge of the mechanisms governing muscle and adipose development. To do this, we must study distribution of the adipose tissue in the whole animal and the cellular aspects of that development, adipocyte ability to synthesize fatty acids or to assimilate nutritional lipids and adipocyte faculty of releasing fatty reserves. In studying muscle tissne. 
its structural development, composition and histological pattern must be taken into consideration.

All these aspects are investigated in this study. The adipose tissue in lamb, located in different regions, shows great diversity in growth rate. At the cellular level, the developmental pattern of adipocyte number and size varies considerably. The metabolic activity of the different deposits studied is found to depend on their anatomical location and the age of the animal.

Analysis shows a great diversity in the protein components of muscle tissue. The structural and biochemical characteristics of muscle change considerably during development, particularly at the early stages. Mietabolic differentiation, however, continues until the muscle is mature. Muscles are made up of different types of fibres, and the proportion of these types differs in different mature muscles. This work demonstrates that there is great diversity in the growth patterns of both adipose and muscle tissue. It is felt that a better understanding of the development and diversity of these tissues is necessary before the quality and quantity of meat in the carcass can be greatly improved.

\title{
The quality of sheep carcasses
}

\author{
R. BOCCARD $\left({ }^{*}\right)$ and B. L. DUMONT $\left({ }^{* *}\right)$ \\ (*) Station de Recherches sur la viande. Centre de Recherches de Clermont-Ferrand, I.N.R.A., \\ Theix 63110 Beaumont \\ (**) Labovatoire de Recherches sur la Viande, C.N.R.Z.I.N.R.A., 78350 Jony-en-Josas
}

Consumers, housewives and retailers have their own definitions of quality based on different single or combined factors.

I. The technological value of the carcass cannot be determined by comparing the proportion of the different cuts (even though they have been obtained by a constant method of cutting) because of the anatomical harmony in the carcass. Tissue distribution is a more reliable measure, but demands dissection of the whole carcass or part of it, such as the shoulder.

Fatness, the most variable tissue characteristic, can be estimated by thickness of subcutaneous fat or even by kidney fat. The tissue composition of the carcass, and especially fat, is largely influenced by sex, age, weight and rate of growth.

The general shape of the carcass, or part of it, generally called conformation, can be described by external measurements after they have been corrected for the effect of weight.

Meat flavour and colour are quality parameters important to consider. A good appraisal of the colour can be obtained chemically or physically; the most important characteristic in evaluating fat is consistency.

Even though the main characteristics of carcass and meat quality are measurable, their combination remains uncertain and needs more clarification.

2. The commercial value of a carcass is determined by various factors such as weight, sex, conformation and fatness, as well as colour and other aspects of meat and fat; these are all characteristics which can be coded. The present emphasis on certain carcass and meat characteristics in the market is sure to change as knowledge of their impact on the technological aspect and value progresses. 